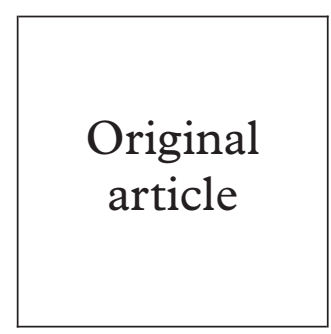

\title{
Behavioural intervention trials for HIV/STD prevention in schools: are they feasible?
}

Judith M Stephenson, Ann Oakley, Susan Charleston, Amanda Brodala, Kevin Fenton, Ann Petruckevitch, Anne M Johnson

Objective: To assess the feasibility of conducting a large randomised controlled trial (RCT) of peer led intervention in schools to reduce the risk of HIV/STD and promote sexual health.

Methods: Four secondary schools in Greater London were randomly assigned to receive peer led intervention (two experimental schools) or to act as control schools. In the experimental schools, trained volunteers aged 16-17 years (year 12) delivered the peer led intervention to 13-14 year old pupils (year 9). In the control schools, year 9 pupils received the usual teacher led sex education. Questionnaire data collected from year 9 pupils at baseline included views on the quality of sex education/intervention received, and knowledge and attitudes about HIV/AIDS and other sexual matters. Focus groups were also conducted with peer educators and year 9 pupils. Data on the process of delivering sex education/intervention and on attitudes to the RCT were collected for each of the schools. Analysis focused on the acceptability of a randomised trial to schools, parents, and pupils.

Results: Nearly 500 parents were informed about the research and invited to examine the study questionnaire; only nine raised questions and only one pupil was withdrawn from the study. Questionnaire completion rates were around $90 \%$ in all schools. At baseline, the majority of year 9 pupils wanted more information about a wide range of sexual matters. Focus group work indicated considerable enthusiasm for peer led education, among peer educators and year 9 pupils. Class discipline was the most frequently noted problem with the delivery of the peer led intervention.

Conclusion: Evaluation of a peer led behavioural intervention through an RCT can be acceptable to schools, pupils, and parents and is feasible in practice. In general, pupils who received the peer led intervention responded more positively than those in control schools. A large RCT of the long term (5-7 year) effects of this novel intervention on sexual health outcomes is now under way.

(Sex Transm Inf 1998;74:405-408)

Keywords: HIV/STD prevention; behavioural interventions; peer led sex education

\section{Introduction}

HIV/AIDS and STDs are major threats to the health of young people, and effective strategies are clearly needed to reduce sexual risk taking in this population. ${ }^{1-3}$ Agreement about the need for such improvement contrasts sharply with debate about the means of achieving it. Much of the confusion reflects lack of evidence about what is effective. A recent review ${ }^{4}$ of behavioural interventions for young people concluded that there have been few methodologically sound studies of their effectiveness in terms of reducing the negative consequences of sexual behaviour. The review called for greater use of the randomised controlled trial for evaluating interventions in this area of health promotion.

Sex education in schools provides a key opportunity for primary prevention because it reaches the vast majority of young people, but its quality and content are variable, and its impact disputed. ${ }^{5}$ However, there is some agreement about the components of sex education most likely to promote sexual health in young people. ${ }^{45}$ They include skills based interventions with information and practical resources to target knowledge and behavioural outcomes. Peer led (sex) education, defined as teaching or sharing of (sexual health) infor- mation, values, and behaviours by members of a similar age or status group, incorporates these components and is gaining popularity. ${ }^{6}$ Hence the need for rigorous evaluation of the impact of peer led interventions on young people's sexual health. We report here on a study in four schools, designed to test the feasibility of conducting a large randomised controlled trial of a peer led intervention to reduce sexual risk taking in secondary schools.

\section{Methods}

SCHOOLS

We selected four schools in Greater London for the feasibility study. Schools had to be mixed sex, state secondary schools with pupils aged 11-18 years to be eligible for the study. (Although sixth form colleges are now common in some areas, 11-18 years is still the most common age range for English secondary schools.) One pair of schools was selected to represent inner city schools, the other suburban comprehensive schools. One school from each pair was randomly assigned to the peer led intervention.

\section{PEER LED INTERVENTION}

The intervention is based on a peer led sex education programme developed by the Ibis 
Trust, a charitable organisation formed in 1985 to provide better sexual health education for young people in response to the HIV epidemic. The programme, which has been conducted in a wide range of schools over the past few years, involves expert training and support of "peers" from year 12 (aged 16-17) to deliver sex education to year 9 pupils (aged 13-14 years). The year 12 peers are genuine volunteers. They are not selected according to specific criteria, but some adopt more active roles than others as the training proceeds. The content of the intervention complies with the school's sex education policy, and the peers are bound by the same rules of confidentiality and disclosure as the school staff. The intervention can use a variety of teaching methods, including role play, question and answer games, drama events, etc. The time devoted to the training and delivery of the programme depends to some extent on what is allowed by each school.

For the purpose of this research project, aspects of the peer led programme, such as the amount of training and topic areas covered, were standardised as far as possible. Nineteen females and four males volunteered to be peer educators in one school, with 20 females and four males in the other. The training involved a weekend outside school, plus two timetabled sessions, and the curriculum time allocated to delivering the programme to the year 9 classes was three double periods of personal and social education (PSE). The topics covered in both experimental schools were HIV/STDs, condom use, and the emotional/sexual aspects of relationships. Once the programme had been developed, the peers rehearsed its delivery in front of a small audience including trainers and school staff. The peer educators worked in small mixed sex teams, and all the year 9 class groups were mixed sex. In each school, the peer volunteers split into a minimum of three groups to cover the lessons (given to six classes of year 9 pupils in school one and seven in school two). All the classes received three lessons of 40 minutes each in school one and 45 minutes each in school two. During the delivery of the peer led intervention to the year 9 pupils, no adults were present.

EVALUATION

All 469 year 9 pupils attending the four schools were invited to complete a baseline questionnaire in March/April 1996 and a follow up questionnaire in September/October 1996, an average of 3 months after receiving sex education. The baseline questionnaire included data on sociodemographic status of the pupils, their knowledge about conception, contraception and HIV/STDs, their attitudes to a range of sexual matters, including views on the adequacy of previous school sex education, their perceived competence in condom use, seeking advice, negotiating safer sex, and resisting unwanted pressure. The post intervention questionnaire repeated some of the baseline questions on knowledge and attitudes, and asked the pupils' views about the sex education they had received during the study. Focus group sessions were conducted with the peer educators and with year 9 pupils from both experimental and control schools. All were assured of confidentiality before taking part, and no concerns along these lines were raised.

Data were analysed in accordance with the design and objectives of the study - that is, to establish the feasibility of conducting a large randomised controlled trial (RCT) in schools, not as a trial testing specific hypotheses. Because existing research on young people's attitudes to sex education shows marked differences between males and females ${ }^{78}$ we examined the data separately by sex.

ETHICAL APPROVAL

Ethical approval was sought from the local UCL/ UCLH Joint Committee on the Ethics of Human Research.

\section{Results}

ACCEPTABILITY OF A RANDOMISED TRIAL

One of the key questions addressed in this feasibility study was the acceptability, to schools, parents, and pupils of a randomised trial of sex education. Fourteen $(31 \%)$ of the 45 schools approached in Greater London were initially interested in the study, from which we selected one pair that best represented inner city schools and another that best represented suburban comprehensives. The commonest reason for declining was reluctance to amend the forthcoming school timetable if this had already been fixed. The timing of the approach to schools is therefore critical to participation. Although few schools objected to randomisation per se, most were motivated by the chance of receiving the peer led intervention, which they saw as a desirable alternative to the usual teacher led education.

Because the study involved people aged less than 16 years, a critical issue was whether or not parents would need to give signed consent before any year 9 pupil could take part. The ethics committee was initially in favour of this option, but the schools were not because they felt that some informed parents would intend no response to convey tacit consent. The alternative was an "opt out" system of consent, whereby informed parents would be assumed to consent unless they indicated otherwise. Another key issue was whether parents were being asked to consent to the peer led intervention itself (in two of the schools) as well as the means of evaluation (that is, questionnaires, and possibly interviews or focus group discussion) or to the evaluation alone. It was eventually decided by the ethics committee that parental consent should be sought for evaluation alone because this type of intervention had been used in schools before but not examined in a research context. Neither the school's responsibility to determine the form of sex education provided, nor the parents' right to withdraw their children from sex education were affected by the pilot study. After letters had been sent to nearly 500 parents informing them about the research study, nine parents contacted a member of the research team. Six parents requested a copy of the questionnaire and made no further contact after this was sent 
to them. The other three parents expressed interest in the study and had questions which were answered by phone. Only one pupil (from a control school) was subsequently withdrawn from filling in the questionnaire. It was made clear to year 9 pupils that they did not have to fill in the questionnaires or take part in the discussions if they preferred not to, but signed consent was not asked for.

RESPONSES OF YEAR 9 PUPILS TO THE BASELINE QUESTIONNAIRE

Around $90 \%$ of the 469 year 9 pupils attended the lessons devoted to questionnaire completion at baseline. Absentee rates ranged from $6 \%$ to $10 \%$, with no appreciable difference between control and experimental schools. All pupils who attended the lessons attempted to complete the questionnaire. Forty nine per cent were female, $51 \%$ lived in privately owned accommodation, and $26 \%$ were from black and ethnic minority groups.

There was considerable agreement between males and females on the quality of sex education received in school so far (table 1). The best covered topic was about bodily development, while the worst were homosexual relationships and diseases caught from having sex. For seven of the 10 topics, a higher proportion of the girls than the boys wanted more information. The topics on which the highest proportion of both sexes wanted more information were HIV/ AIDS, STDs, and where to get advice. Although regard for previous teaching about homosexuality was poor, it was the least popular topic for further information (table 1). The majority of pupils $(64 \%$ of girls and $74 \%$ of boys) had received sex education in school from a teacher; a "visitor to the school" was

Table 1 Adequacy of previous school sex education in 228 female and 235 male pupils aged 13-14 years (experimental and control schools combined)

\begin{tabular}{|c|c|c|c|c|}
\hline \multirow[b]{2}{*}{ Topic } & \multicolumn{3}{|c|}{ How well topic was covered (\%) } & \multirow{2}{*}{$\begin{array}{l}\text { Proportion } \\
\text { wanting mor } \\
\text { information }\end{array}$} \\
\hline & Well & $O K$ & Not well & \\
\hline \multicolumn{5}{|c|}{ Contraception } \\
\hline Females & 41 & 23 & 35 & 71 \\
\hline Males & 39 & 27 & 37 & 62 \\
\hline \multicolumn{5}{|l|}{ HIV/AIDS } \\
\hline Females & 26 & 24 & 49 & 81 \\
\hline Males & 37 & 21 & 42 & 66 \\
\hline \multicolumn{5}{|c|}{ Other diseases caught from having sex } \\
\hline Females & 14 & 22 & 64 & 81 \\
\hline Males & 19 & 23 & 58 & 66 \\
\hline \multicolumn{5}{|c|}{ Lesbian and homosexual relationships } \\
\hline Females & 6 & 15 & 79 & 48 \\
\hline Males & 8 & 17 & 75 & 30 \\
\hline \multicolumn{5}{|c|}{ How not to have sex when you don't want to } \\
\hline Females & 18 & 22 & 60 & 71 \\
\hline Males & 18 & 22 & 59 & 65 \\
\hline \multicolumn{5}{|c|}{ How young people's bodies develop } \\
\hline Females & 60 & 23 & 16 & 56 \\
\hline Males & 53 & 23 & 23 & 57 \\
\hline \multicolumn{5}{|c|}{ Sexual feelings, emotions, and relationships } \\
\hline Females & 24 & 28 & 46 & 64 \\
\hline Males & 26 & 27 & 47 & 64 \\
\hline \multicolumn{5}{|c|}{ What people do when they have sex } \\
\hline Females & 31 & 17 & 51 & 56 \\
\hline Males & 29 & 26 & 45 & 63 \\
\hline \multicolumn{5}{|l|}{ Pregnancy } \\
\hline Females & 33 & 28 & 38 & 75 \\
\hline Males & 47 & 26 & 27 & 57 \\
\hline \multicolumn{5}{|c|}{ Where to get advice on any of the above } \\
\hline Females & 28 & 25 & 47 & 80 \\
\hline Males & 30 & 25 & 45 & 68 \\
\hline
\end{tabular}

recalled by $31 \%$ of girls and $12 \%$ of boys, and the "school nurse" by $31 \%$ of girls and $12 \%$ of boys.

QUALITATIVE EVALUATION

The social interaction between the year 9 pupils and the peer educators was explored qualitatively through focus group discussions. There was agreement among the peers that the features which made the peer led sessions quite distinct from previous sex education included their non-authoritarian status, which made them "more on a sort of level" with the younger pupils, and their verbal and body language, which "was much different from the teachers, more relaxed". When asked "what kind of vocabulary did you use?" one peer answered "just how we usually speak . . . and we didn't speak to them like year $9 \mathrm{~s}$, we spoke to them like sort of equals". Another peer educator said that her team's initial approach had been formal, standing at the blackboard and using the flip chart, but in later lessons the peers would sit with the year 9 pupils in a circle or sit on desks and "slouch about like they [the year 9 pupils] want to be able to do". Two other peers mentioned that the novelty of the classes excited curiosity among the year 9s which was thought to be a good thing. One outlined what the peer sessions were trying to achieve. "It wasn't about learning it was about attitudes, it's more that they should be going away questioning issues that they'd brought up."

Problems with class discipline were experienced to some degree by all the peer teams. This was not helped by their lack of authority. As one peer said "They [the year 9 pupils] know we don't have the authority to send them to the headmaster and so from that sense there was nothing we could do apart from telling them to shut up, which they ignored anyway." Confidence and assertiveness skills were commonly mentioned by the peer educators as the skills most needed for the programme. The peers also noted marked sex differences. Comments such as "the girls were much more responsive than the boys" and "girls were much more mature" were common.

Focus group sessions with the year 9 pupils showed that peer led sex education was generally welcomed. The importance of shared language was noted again. One year 9 pupils said "you could speak like normally like you would with your friends about stuff, you weren't frightened that you'd use a bad word." Another said "I don't think you get the chance to talk a lot in other classes. I don't know, it's more difficult to just speak out on like sensitive things."

Focus groups with year 9 pupils in the control schools implied an excessive focus on biological aspects of sex education. As one pupil said, "We do the same subject every time, all about puberty and development. I don't think they can think of anything else to teach us." Another said "It's like that's a safe topic and they [the teachers] have got all the leaflet and pictures to give out." When asked what other things they would like to be covered, another pupil replied "I don't know ... the next 
step on from puberty and stuff . . relationships and places to go if you need help."

\section{Discussion}

The need to reduce the risk of HIV/AIDS, STD and unwanted pregnancy in young people is clear, but deciding how best to intervene is less straightforward. Sex education in schools offers a potentially efficient means of intervening before sexual activity begins, but the role and the impact of school sex education continue to arouse public debate. ${ }^{19}$ Opposing views are often deeply entrenched, despite lack of direct evidence to indicate either positive or negative effects on sexual health. ${ }^{5}$ Surveys and qualitative studies show a high level of dissatisfaction with sex education among many young people and considerable differences between the needs of young women and young men. ${ }^{70}$ These factors highlight the importance of conducting well designed evaluations of sex education using both quantitative and qualitative methods. Most school teaching is evaluated in terms of its impact on knowledge, not behaviour outside the classroom. Studies of sex education that use sexual health or behavioural outcomes are far more demanding and can be difficult to conduct in schools. They require close collaboration between medical and social scientists and educationalists, and careful testing of methods and follow up procedures. The challenges posed by a large scale school based RCT of sex education provided the rationale for our feasibility study.

The results of the study show that it is feasible to conduct an RCT of a peer led intervention in schools to reduce the risk of HIV/STD and promote sexual health. Enough schools were willing to enter the study, and to be randomised either to receive the peer led intervention or not. The method of informing parents worked well and schools were enthusiastic about the study. The feasibility study yielded a number of important lessons for the main trial. These included the importance of timing the approach to schools to fit in with the school year, the constraints with which schools have to work, and the need to provide some incentive for control schools to compensate them for not receiving an intervention which is widely perceived as desirable. For the main trial (see below), financial incentives are being offered to control schools.

The issue of ethical approval for the study was very instructive. There was much discussion about whether approval was needed from an independent body, such as a research ethics committee, in addition to that of the school staff and governors. Recruitment of young people to research projects is a sensitive area, especially the relative merits of active (opt in) versus passive (opt out) parental consent. ${ }^{11}{ }^{12}$ For this study, the ethics committee decided to approve either method, depending on guidance from individual schools.

The focus group data collected from the young people who took part in the study suggest that peer led intervention did provide something different from the more usual teacher led sex education. The peer leaders and the year 9 pupils expressed the view that the sessions gave them more opportunity to raise questions and discuss sensitive issues in their own language. The differences in attitudes to sex education we found between males and females generally parallel those found in other studies. $^{78}$

Moving on from the experience of this pilot study, we are now conducting a large randomised trial of peer led sex education in 27 schools in southern England with long term follow up to age 19 . The number of schools was based on the statistical power needed to detect a reduction in the cumulative rate of termination of pregnancy at age 19. Before randomisation, schools were stratified according to an assessment of baseline risk status based on factors related to teenage pregnancy, including socioeconomic status, educational attainment, the quality of current school sex education, and accessibility of local family planning services. To date, we have carried out the baseline survey in over 4000 pupils from the 27 schools.

In conclusion, there is clearly a need to improve the sex education that young people are currently getting at school. Peer led intervention is a promising approach. The results of this study show that a large RCT of a peer led intervention in secondary schools is a feasible way to move towards a more scientific examination of the long term effectiveness of sex education in promoting sexual health.

We thank all the schools and pupils who took part in this pilot study.

Three of the authors (JS, AP, and KF) are supported by an MRC programme grant. The study was funded by the DepartMRC programm
ment of Health.

Disclaimer: The work was undertaken by Dr J Stephenson, Professor A Oakley, Ms S Charleston, Ms A Brodala, Dr K Fenton, Ms A Petruckevitch, and Professor A M Johnson, who have received funding from the Department of Health. The views expressed in this publication are those of the authors and not necessarily those of the Department of Health.

1 Genuis SJ, Genuis SK. Adolescent sexual involvement: time for primary prevention. Lancet 1995;345:240-1.

2 Catchpole M. Sexually transmitted diseases in England and Wales: 1981-1990. CDR 1992;2:R1-12.

3 Adler MW. Sexual health - a Health of the Nation failure. BMF 1997;314:1743-7.

4 Oakley A, Fullerton D, Holland J, et al. Sexual health education interventions for young people: a methodological review. $B M 7$ 1995;310:158-62.

5 Kirby D, Short L, Collins J, et al. School-based programs to reduce sexual behaviors: a review of effectiveness. Public Health Reports 1994;109:339-60.

6 Editorial. Sex education in schools: peers to the rescue? Lancet 1994;344:889-90.

7 Woodcock A, Stenner K, Ingham R. "All these contraceptives, videos and that..."Young people talking about school sex education. Health Education Research 1992;7: 517-31.

8 Abraham C, Sheeran P, Abrams D, et al. Young people Abraham C, Sheeran P, Abrams D, et al. Young people sources. Health Education Research 1991;6:19-20.

9 Dean M. Muddle over sex education. Lancet 1994;343. 1149.

10 Ray C. Highlight: sex education. Sex Education Forum 1994; 28

11 Ellickson PL, Hawes JA. An assessment of active versus passive methods for obtaining parental consent. Evaluation Review 1989;13:45-55.

12 Esbensen F-A, Deschenes EP, Vogel RE, et al. Active parental consent in school-based research. An examination of ethical and methodological issues. Evaluation Review 1996; 20:737-53. 